UC-2R

Issued: November 1984

LA $-10277-$ HS

DE85 005196

\title{
Design of Ferrite-Tuned Accelerator Cavities Using Perpendicular-Biased High-Q Ferrites
}

\author{
Klaus Kaspar*
}

\author{
DISCLAIMER
}

\begin{abstract}
This report was prepared as an account of work sponsored by an agency of the United States Government. Neither the United States Government nor any agency thereof, nor any of their employees, makes uny warranty, express or implied, or assumes any legal liability or responsibility for the accuracy, completeness, or usefulness of any information, apparatus, product, or process disclosed, or represents that its use would not infringe privately owned rights. Reference berein to any specific commercial product, process, or service by trade name, trademark, manufucturer, or otherwise does not necessarily constitute or imply its endorsement, recommendation, or favoring by the United States Government or any agency thereof. The views and opinions of authors expressed borein do not nocessarily state or reflect those of the United States Government or any agency thereof.
\end{abstract}

'Coliaborator ar Los Alamos. Gesellschaft fuer Schwerionen-forschung. Postfach 110541. 1500 Darmstadt 11, WEST GEFMANY.
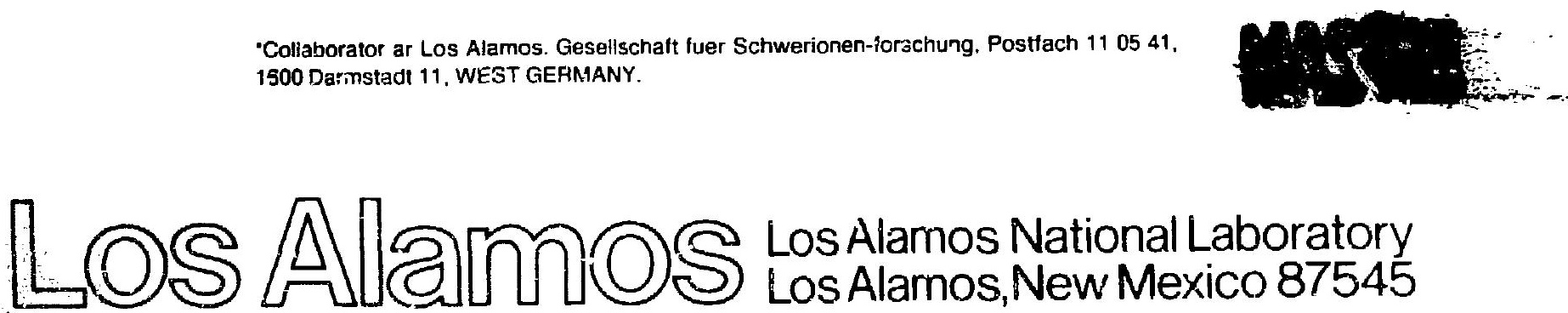


\title{
DESIGN OF FERRITE-TUNED ACCELERATOR CAVITIES \\ USING PERPENDICULAR-BIASED HIGH-Q FERRITES
}

by

\section{Klaus Kaspar}

\begin{abstract}
Microwave ferrites with dc bias fields perpendicular to the rf fields exhibit magnetic and dielectric quality factors 1 order of magnitude above that of ferrites used in ferite-tuned synchrotron accelerating cavities butlt In the past. For the LArPF II project, these ferrites appear to allow the design of synchrotron cavities with high gap voltages and high efficiency. A simple coaxial quarter-wave-resonator geometry, first considered only as a model for preliminary studies, turned out to be a good basis for the solution of most technical problems sich as generation of the bias fleid, cooling of the ferrites, and installation of a generous high-voltage gap design. Two quarter-wave resonators combined to :orm c ne accelerating unit of about 2.5-m length and $0.6-\mathrm{m}$ diameter should be capable of delfvering $120 \mathrm{kV}$ of accelerating voltage in the tuning range 50-60 MHz, up to $200 \mathrm{kV}$ in the range 59-60 MHz. The main advantage of the given resonator design is its full rotational symmetry, which allows calculation and optimization of all electrical properties with maximum reliability.
\end{abstract}

\section{INTRODUCTION}

Synchrotron cavities have been built for wore than 30 years and for more than 20 synchrotron facilities. Among the variois methods tried for controlling the resonant frequency of the cavities, only dc bias flelda with field lines parallel to the magnetic rf fleld lines have been used. Many of the difficulties and limitations of these ferrite-tuned cavities can be reduced or avolded if the dc bias field is applied perpendicular to the magnetic if field. ${ }^{-3}$ After model measurements ${ }^{*}$ were performed at Los Alamos, we studied

\footnotetext{
\#This information was supplied by R. D. Carlini, Los Alamos National Laboratory (1984) and W. R. Smythe, Denver, Colorado (1984).
} 
how the bias-field method can be used to design the accelerating svstem for the proposed LAMPF II facility.

\section{THE TE REQUIREMENTS FOR THE LAMPF II FACILITY}

The plan for the LAMPF II project consists of a fast-cycling booster and a main ring. The relevant parameters for the if acceleraring systems are listed in Table $I$.

In both machines, maximum rf voltage per cavity is required to reduce the number and cost of the accelerating stations needed. For the booster, the voltage per cavity is a factor of 2 higher than the voltages used in the most powerful comparable cavities [FNAL (Fermi National Accelerator Laboratory) booster]. For the main ring, similar values to those in the FNAL main ring are used. The number of accelerating stations is quite large even with the design voltages per cavity as specified.

III. REVIEW OF THE PROPERTIES OF PARALLEL-BIASED FERRITES

In existing synchrotron cavities, the ferrites are usually operated from

near initial permeability to near saturation, which means that the region of

TABLE I

PARAMETERS FOR THE DESIGN OF THE LAMPF II rf SYSTEM

$\begin{array}{lccc} & \text { Booster } & \text { Main Ring } \\ \text { Energy range (GeV) } & 0.800-9.000 & 9.000-45.00 \\ \text { Repetition rate (Hz) } & 60 & 10 & 30 \\ \text { Rise time of cycle (ms) } & 50.60-59.70 & 59.70-60.00 \\ \text { Accelerating frequency (MHz) } & 2000 & 5000 \\ \text { Energy gain per revolution (keV) } & 4000 & 10000 \\ \text { Required peak rf voltage (kVp) } & 34+6 & 72+8 \\ \text { Number of accelerating cavities } & 120 & \\ \text { Peak voltage per cavity (kVp) } & 2 \cdot 10 & 4.40 \\ \text { Maximum proton intensity (p/s) } & 1.6 & \\ \text { Average beam current (A) } & 3.2 & 1.6 \\ \text { Current at accelerating frequency (Ap) } & 180 & 3.2 \\ \text { Beam loading per cavity (kWp) } & & 180\end{array}$


motion at domaln boundaries is included in the tuning cycle. There are two reasons: (1) the requirements for the generation of a high dc bias field are lowered, and (2) using the full perweability range of the ferrite is probably the only way to vary the resonant frequency of accelerating cavities by factors of 3 and more. The highest efficiency of the dc bias fleld is obtained when the bias field uses the same closed magnetic circuit as does the rf magnetic field; this means the bias field is parallel to the rf fleld.

The capabilities of ferrite-tuned cavities are deter ined and limited by the properties of the fezrite material. Some of the characceristic properties are the following:

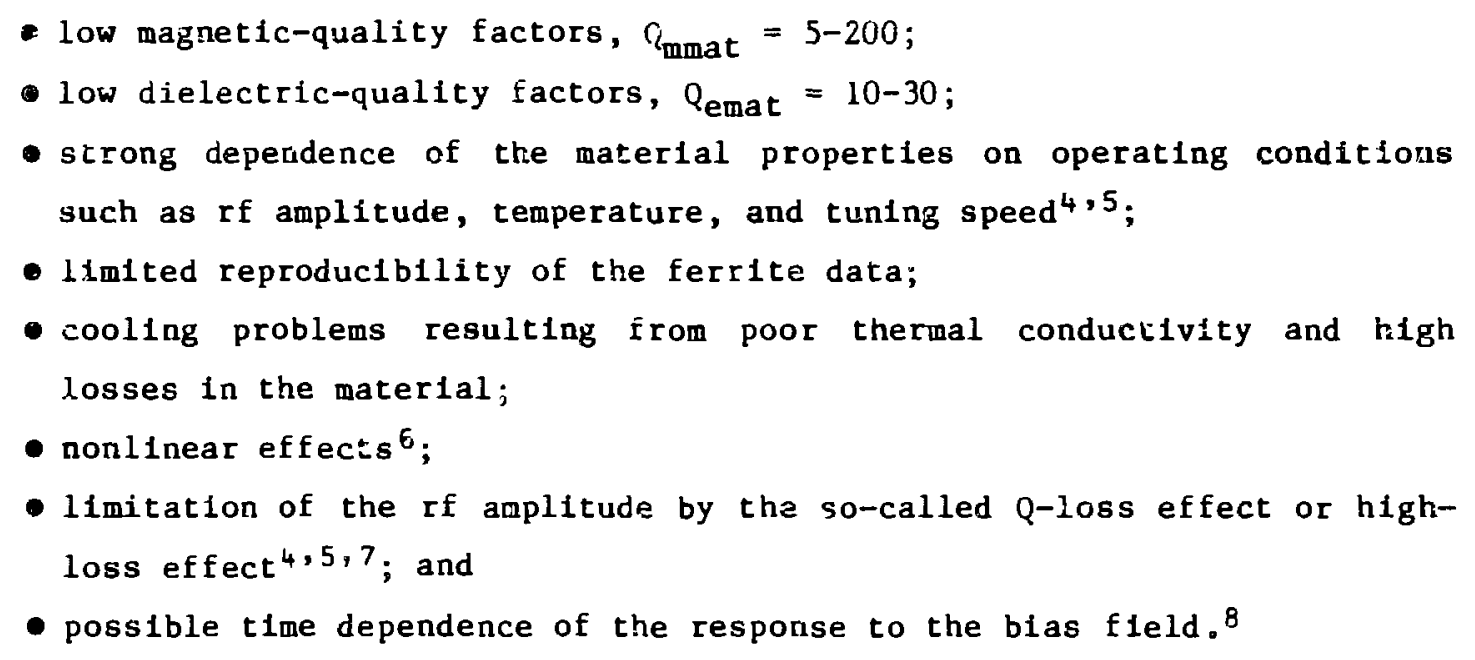

- limitation of the rf anplitude by tha so-called Q-1oss effect or highloss effect $4,5,7$; and

- possible time dependence of the response to the bias fleld.8

Some of the effects are not fully understood and/or cannot be reproducibly controlled.

\section{PROPERTIES OF PERPENDICULAR-BIASED FERRITES}

Ferrites with dc blas are used in various microwave applications such as phase shifters, controlled attenuators, and modulators. Most of the problems and restrictions known from synchrotron cavities seem not to exist in these applications. The reasons for the very different ferrite properties can, on the one hand, be explatned by the spectal compositions of and the more refined production methods used for these materials. On the other hand, it is assumed that the main differences are due to the fact that the ferrites are operated near saturation and with the dc bias field perpendicular to the rf magnet $\perp C$ fields, Under these conditions the ferrites show the following properties: 
- very high magnetic $Q$ values, $Q=1000-5000$;

- very high electric $Q$ values, $Q=\sim 1000$, and

- low dependence of the macerial properties on rf amplitude, tuning speed, and other operating conditions.

For the LAMPF II project it has been proposed to use microwave ferrites and the perpendicular bias method for the design of the accelerating cavities. ${ }^{-3}$ Model measurements with several microwave ferrite types in the range 60-80 $\mathrm{MHz}$ exhibited the same advantageous ferrite properties known at nicrowave frequencies. * Whereas the measurements give evidence of considerably higher magnetic $Q$ values, we use as a Dasis a "worst-case" magnetic $Q$ value of $Q_{\text {mat }}=1000$ over the whole frequency $r$ ange.

\section{SIMPLE QUARTER-WAVE-CAVITY CONCEPT FOR LAMPF II}

The following studies are based on the discussion of the simplest case of a coaxial quarter-wave resorator as shown in Fig. 1 . On the one hand, this geometry is sufficient to describe the transmission-1ine formalism used for calculation and to discuss most of the technical problems arising from the perpendicular bias of the ferrites. On the other hand, this simple geometry offers several advantages over more complicated systems. We consider it for the final cavity design as well.

* This infortation was supplied by R. D. Carlini, Los Alamos National Laboratory (1984) and W. R. Smythe, Denver, Colorado (1984).
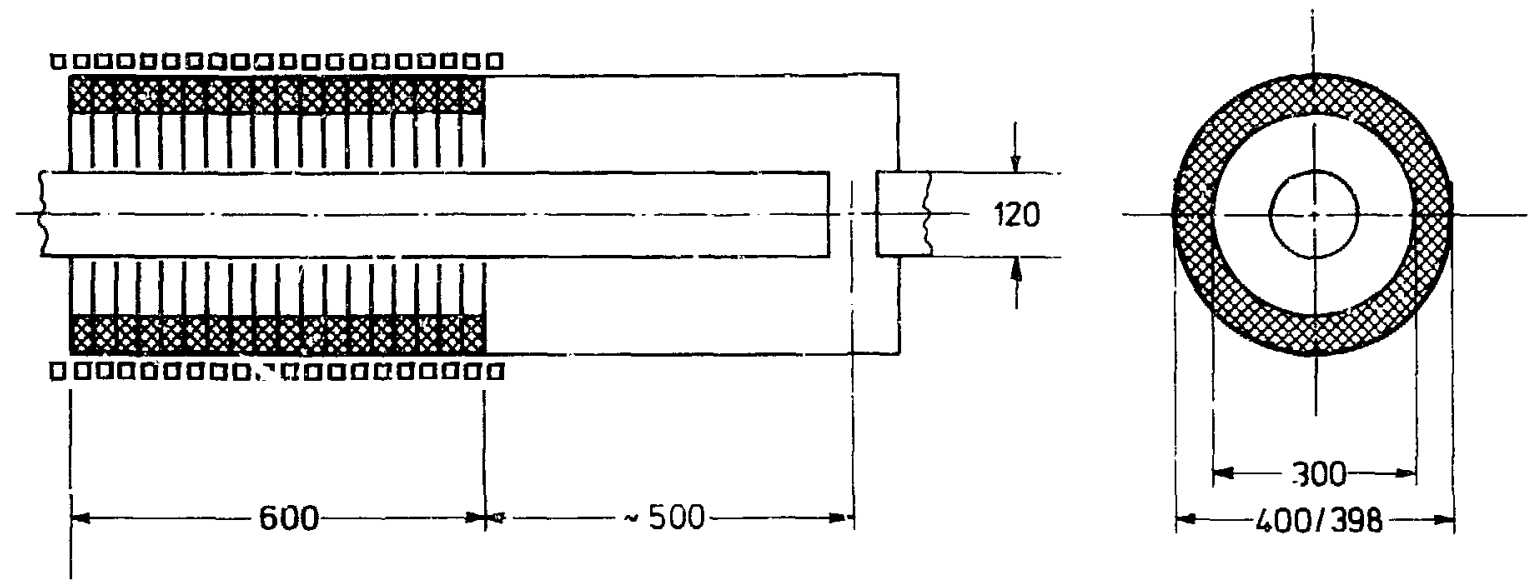

Fig. 1. Coaxial quarter-wave resonator. 
To calculate the rf properties of the given resonator geometry, we treat it as a combination of two homogeneous transmission-line sections. Inhomogeneities appearing around the transition from the tuner to the ferrite-free line section and also in the gap region are neglected. Also, the gap capacity is neglected, which means that the calculated lengths of the ferrite-free line section must be shortened by a length corresponding to the gap length, The results obtained in this way are considered as a first approximation. The transmission-line relations used to calculate the given case, as well as more complicated resonator geometries, are assembled in the Appendix.

Table II shows the data calculated for two cavity examples with the same radial dimensions but with different lengths for the tuner sections. The first column describes the design proposed for the LAMPF II booster cavities; the second column desc-ibes the resonator proposed for the main ring.

Both examples are calculated to have the same permeability, $\mu_{\text {mat }}=2.0$ at $60 \mathrm{MHz}$. As a result, at $60 \mathrm{MHz}$ and with the sane gap voltage, the maximum rf currents and the maximum magneti: power densities are nearly the same in both cases. The permeability and bias-field variation required to tune the cavities from 60 to $50 \mathrm{MHz}$ would be considerably larget for the short tuner version. The advantages of the longer tuner for large: frequency variations are evident. However, an increase of the tuner length to more than $600 \mathrm{~mm}$ leads to a relatively small length of the ferrite-free line section. The space around this section is useful for installation of a sufficiently long ceramic gap insulator and is better reserved for this purpose.

In both exampies the magnetic and the electric $Q$ values are put at very pessiristic values. Probably both values can be assumed to be at least a factor of 2 larger.

In the case of very small frequency variations, as in the main $r i n g$, the shorter tuner is adequate. With the high bias fields required for $60 \mathrm{MHz}$, larger magnetic $Q$ values are relatively certain. It seems possible to run the given main-ring cavity design to gap voltages above the $100-\mathrm{kV}$ peak per quarter-wave resonator, though only $70 \mathrm{kV}$ are assumed in Table II. The shorter tuner has the advantiage that the ferrite stays completely our of the high electric-power-density region; on the other hand, it provides additionă space to install a longer ceramic gap insulator if that is needed. 
TABLE II

CALCULATED DATA FOR COAXIAL CAVITYa

Cavity dimenstons

Cavity outer diameter (mm)

Cavity inner diameter ( $\mathrm{mm}$ )

Ferrite outer diameter (mm)

Ferrite inner diameter ( $\mathrm{mm})$

Length of tuner ( $\mathrm{mm}$ )

Length of free line (m)

Operating frequency ( $\mathrm{MHz}$ )

Gap voltage ( $k v$ )

Transformation $\left(V_{g, a p} / V_{t}\right)$

Max. tuner rf current (A)
Booster

400

120

398

300

600

500

$50.0-60.0$

$60.0-60.0$

$1.16-1.24$

0.85-0.98
Main Ring

40C

120

398

300

200

1000

$59.5-60.0$

$70.0-70.0$

3.17-3.2?

$0.97-0.97$

Ferrite material data

Material permeability ( $\mu_{\text {mat }}$ )

Material perwittivity ( $\varepsilon_{\text {mat }}$ )

ignetic quality factor ( $\left.Q_{\text {mmat }}\right)$

Electric quality factor ( $Q_{\text {euat }}$ )
5.56-2.00

$14.0-14.0$

1000-1000

100-100
$2.24-2.00$

$14.0-14.0$

1000-1000

100-100

Maximum power densities

Magnetic, point $A\left(\mathrm{H} / \mathrm{cm}^{3}\right)$

$0.54-0.38$

$0.55-0.50$

Magnetic, point B $\left(W / \mathrm{cm}^{3}\right)$

$0.18-0.1$ ?

$0.50-0.45$

Electric, point $B\left(W / \mathrm{cm}^{3}\right)$

$0.13-0.14$

$0.03 \cdot 0.03$

Total peak power losses

Magnetic losses in tuner (kW)

$9.63-6.78$

$4.28-3.98$

Losses in cavity walls ( $\mathrm{kW}$ )

$1.10-1.60$

$2.40-2.4 \mathrm{C}$

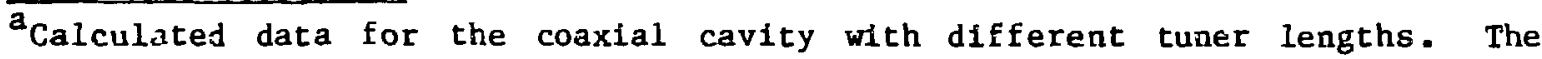
additional space required for ferrite cooling has been neglected. Inhomogeneities between the tuner and the ferrite-free line section and in the gap region have been neglected as well. All power data are peak values without considering duty factor.
} 
VI. GENERATION OF THE PERPENDICULAR dC-BIAS FIELD

It is assumed that the dc bias field $H_{d c}$ needed to realize a certain ferrite permeability $\mu_{\text {mat }}$ can be calculated from the material's saturation magnetization $4 \pi \cdot M_{S}:^{*}$

$$
\mu_{\text {mat }}=1+4 \pi \cdot M_{s} / H_{d c}
$$

Microwave ferrites with saturation magnetizations as low as $4 \pi \cdot M_{S}=$ 300-600 G are available from several firms. Samples with $4 \pi \cdot M_{S}=600$ have been measured at Los Alamos and seem to satisfy all requirements. ${ }^{* *}$ Fcr these samples one obtains

$$
H_{\mathrm{dc}}=16-48 \cdot 10^{3} \mathrm{~A} / \mathrm{m} \text { for } \mu_{\mathrm{mat}}=4.0-2.0 \text {. }
$$

It is difficult to calculate how much the applied external magnetic field will be reduced by polarization of the ferrite, inhomogeneous field distribution, and other effects. Therefore, the above value is multiplied by a safety factor of two and a maximun value of $\mathrm{H}_{\mathrm{dc}}=10^{5} \mathrm{~A} / \mathrm{m}$ is used for further discussion. It seems possibie to realize this bias field by means of a water-cooled high-current solenoid enclosing the ferrite tuner as shown in Fig. 2. A rough estimate leads to the data given in Tabie ILI.

\# This information was supplied by $W$. R. Smythe, Denver, Colorado (1984).

This information was supplied by $R$. D. Carlini, Los Alamos National Labor:tory (1984).

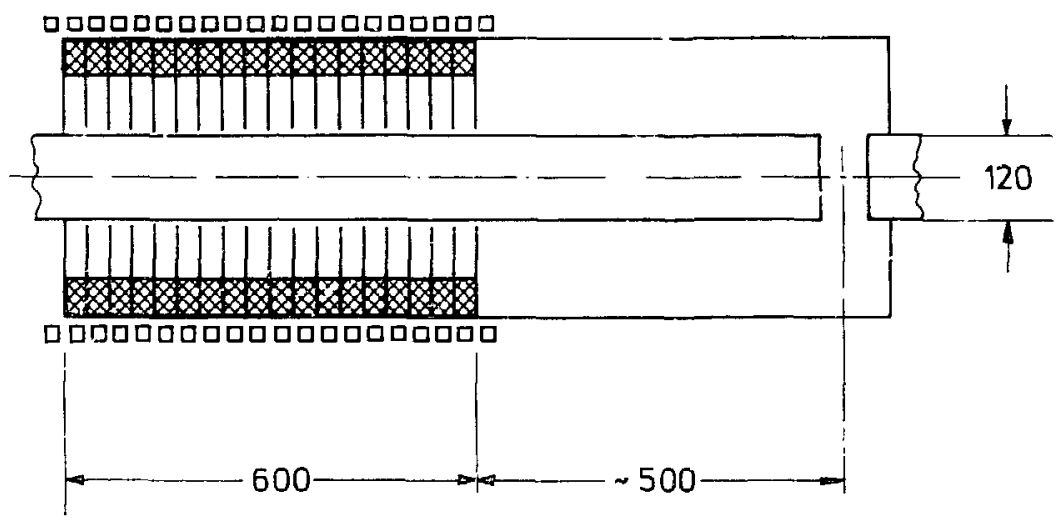

Fig. 2. The dc blas windings in the perpendicular-biased cavity. 
TABLE III

EXPECTED MAXIMUM ELECTRIC DATA FOR THE PERPENDICULAR-BIAS SYSTEM

$\begin{array}{ll}\text { Length } \times \text { diameter of solenoid } & 0.7 \mathrm{~m} \times 0.45 \mathrm{~m} \\ \text { Cross section of conductor } & 2 \times 20 \mathrm{~mm} \times 20 \mathrm{~mm} \\ \text { Number of windings } & 10 \\ \text { Maximum dc bias field } & 100000 \mathrm{~A} / \mathrm{m} \\ \text { Resistance of winding } & 0.32 \mathrm{~m} \Omega \\ \text { Maximum dc current } & 8000 \mathrm{~A} \\ \text { Maximum dc voltage drop } & 3.0 \mathrm{~V} \\ \text { Maximum dc power dissipation } & 24 \mathrm{kH} \\ \text { Maximum self-inductance } & 100 \mu \mathrm{H} \\ \text { Maximum tuning rate (booster) } & 3.20 \mathrm{MHz} / \mathrm{ms} \\ \text { Maximum bias field rate } & 12500 \mathrm{~A} / \mathrm{m} \cdot \mathrm{ms} \\ \text { Maximum bias current rate } & 1000 \mathrm{~A} / \mathrm{ms} \\ \text { Maximum dc voltage } & 65 \mathrm{~V}\end{array}$

The results look extreme at first glance but are comparable with the bias requirements for parallel-biased cavities. For example, each FNAL booster cavity is biased by a 60-kW (30-V/2000-A) bias supply, ${ }^{9}$ and Ref. 10 describes a bias supp $1 \mathrm{Y}$ Jithod delivering $70 \mathrm{~V}$ at the beginning and $5 \mathrm{~V} / 20000 \mathrm{~A}$ at the end of the cycle for a fast-cycling synchrotron cavity. Compared with these, the data in Table IiI seem surprisingly low. The reason is that the ferrites discussed here have been selected for low-saturation magnetization values.

With the bias windings mounted outside the rf resonator, one of the main problems occurring in most parallel-blased cavity designs (decoupling of the bias cilcuit and the $\mathrm{rf}$ resonator) is optimally solved. Instead, the question arises whether the rapidly-varying dc bias field can penetrate the resonator walls without unacceptable losses or disturbance by eddy currents. It is expected that problems of this kind can be avoided by building the outer conductor of the cavity of stainless steel sheet with a thickness less than the skin depth at the maximum-bias field frequency. At $20 \mathrm{kHz}$ the skin depth in stainless sreel is about $2.3 \mathrm{~mm}$. With $0.5-$ to $1.0-\mathrm{mm}$ stainless cavity walls plated on the inside with about 0.02-mm copper, eddy-current effects are probably negligí-ie. 
It seems desirable to use some $k \neq$ nd of magnetic yoke for the magnetic field outside the cavity. The advantages can be lower (or not higher) bias currents, better homogeneity of the fieid inside the ferrite, and reduction of the magnetic stray field outside the cavity. Yoke segments consisting of laminated iron or some cheaper ferrite material assembled around the cavity as indicated in Fig. 3 would be useful for this purpose.

VII. COOLING OF PERPENDICULAR-BIASED FERRITES

The large magnetic and electric quality factors available in microwave ferrites with perpendicular bias reduce the rf losses drastically. However, this advantage is mostly lost by raising the gap voltage per resonator and leads to the point at which ferrite losses are no longer negligible.

Due to the relatively low thermal conductivity of ferrites, the power losses inside the material lead to temperature gradients. The $1 / \mathrm{r}^{2} \mathrm{cistribu-}$ tion of the magnetic and dielectric power densities in a coaxics cavity normally produces high radial temperature gradients. In a coaxial cavity with parallel bias, the dc-bias field goes with $1 / r$ and the resulting power-density distribution becomes nearly corstant with the radius.10 it is not clear whether a similar compensating effect exists or can be generated in a cavicy with a perpendicular-bias field.

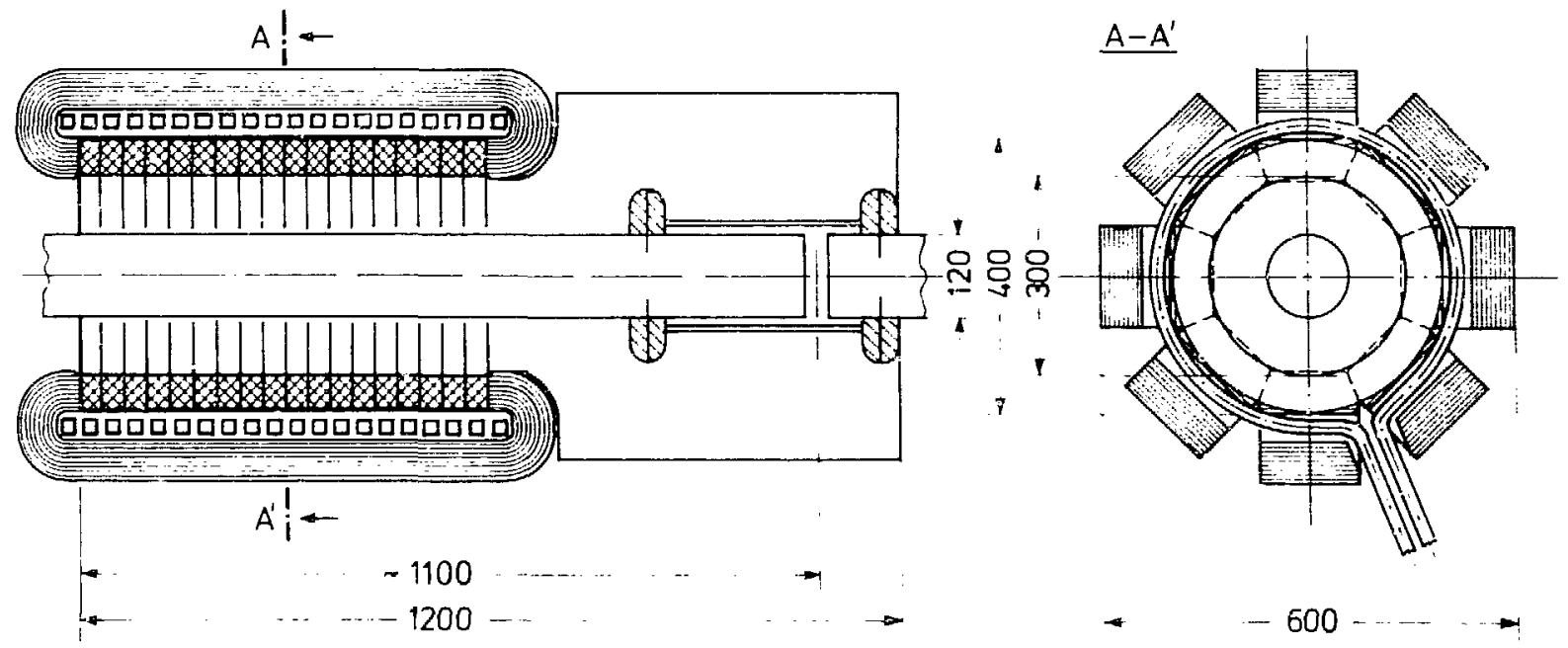

Fig. 3. Possibility of realizing a magnetic yoke around the bias solenuid. The dc-bias solenojd consists of 20 single-turn windings connected outside the yoke to form a 10-turn solenoid winding. 
Large temperature gradients cause large mechanical stresses and may break the ferrite elements. Large local temperatures produce large changes of the magnetic and electric material properties and can lead to thermal f.nstability of the whole system. ${ }^{7}$ Mean power densities of about $0.3 \mathrm{~W} / \mathrm{cm}^{3}$ are considered maximun values for stable operationll; however, higher values have been used without problems.

In existing cavities the tuner section always consists of a stack of ferrite rings cooled by water-cooled copper disks or by an air flow passed through gaps between the rings.

The usual and most effective solution, using water-cooled copper disks between the ferrite rings, has to be excluded from a perpendicular-biased systam because of eddy currents induced in the cooling discs. It seems possible to overcome this problem in the same way as for the outer conductor of the cavity, using cooling disks made of thir stainless sheet. Cooling rings using extremely thin $(0.1-\mathrm{mm})$ stainless membranes have already been discussed at GSI (Gesellschart Für Schwertonen Forschung) for other reasons; such rings would expand under the pressure of the cooling water to give optimum thermal contact with the ferrite surfaces.

Calculations on the rf field distribution in a ferrite stack with inserted cooling plates ${ }^{*}$ revealed considerable, probabiy unfavorable, deviations from the field distribution without cooling plate. The CERN booster cavities are one of the few designs using air cooling. My own calculations, using published data ${ }^{7}$ and assuming $Q_{\text {mat }}=200$ for the CERN ferrites, lead to peak power densities of $0.6 \mathrm{~W} / \mathrm{cm}^{3}$ for these cavities. The peak power densities given in Table II, calculated for relatively pessimistic assumptions for $Q_{\text {mmat }}$, could be kept below this value. Air cooling is considered to be the simplest and most adequate cooling method for the perpendicular-biased cavity design.

\section{DESIGN OF THE ACCELERATING GAP}

The design of the ceramj.c gap seal is one of the most severe problems and may turn out to be the main limitation for the attainable gap voltages. The cavity design considered here provides enough radial and longitudinal space for a generous layout of the gap geometry. The risk of sparkovers can

\footnotetext{
This information was supplied by R. D. Carlini, Los Alamos National Laboratory (1984).
} 
probably be kept low by careful design of the gap, corona rolls, and a suffictently long ceramic gap seal.

If the usual techntque is used, with metal joints brazed to the ends of the ceramic seal, it has to te kept in mind that rf currents in the order of several hundred amperes have to pass over this brazing region, possibly leading to considerabie rf losses and overheating problems.

The operating conditions of the cavities are similen ts those of the FNAT, cavities, where initial problems with the gaps seem to be entirely solved. $12: 13$

The alr cooling proposed for the ferrites will probably be useíul for cosling the gaps as well.

IX. COMBINATION UF TWU QUARTER-WAVE RESONATORS IN UNE CAVITY

With the bias windings completely separate from the rf fields, there is no technical necessity to combine pairs of resunators in each cavity unit, as is the case in nearly all parallel-biased cavities. However, by combining two quarter-wave resonators in eacin accelerating station, the number of $r f$ and control systems can be reduced by a factor of'. Figure 4 shows two resonators coupled to the tuner ends.

For maximum energy gain of the particles, the distance from gap center to gap center should be $\beta \cdot \lambda / 2=2.5 \mathrm{~m}$. With the dimensions given in Table II and with both resonators in closest connection, this distance wiil be about $2.0 \mathrm{~m}$ or $140^{\circ}$. The reduction in energy gain would then be about $10 \%$. In this

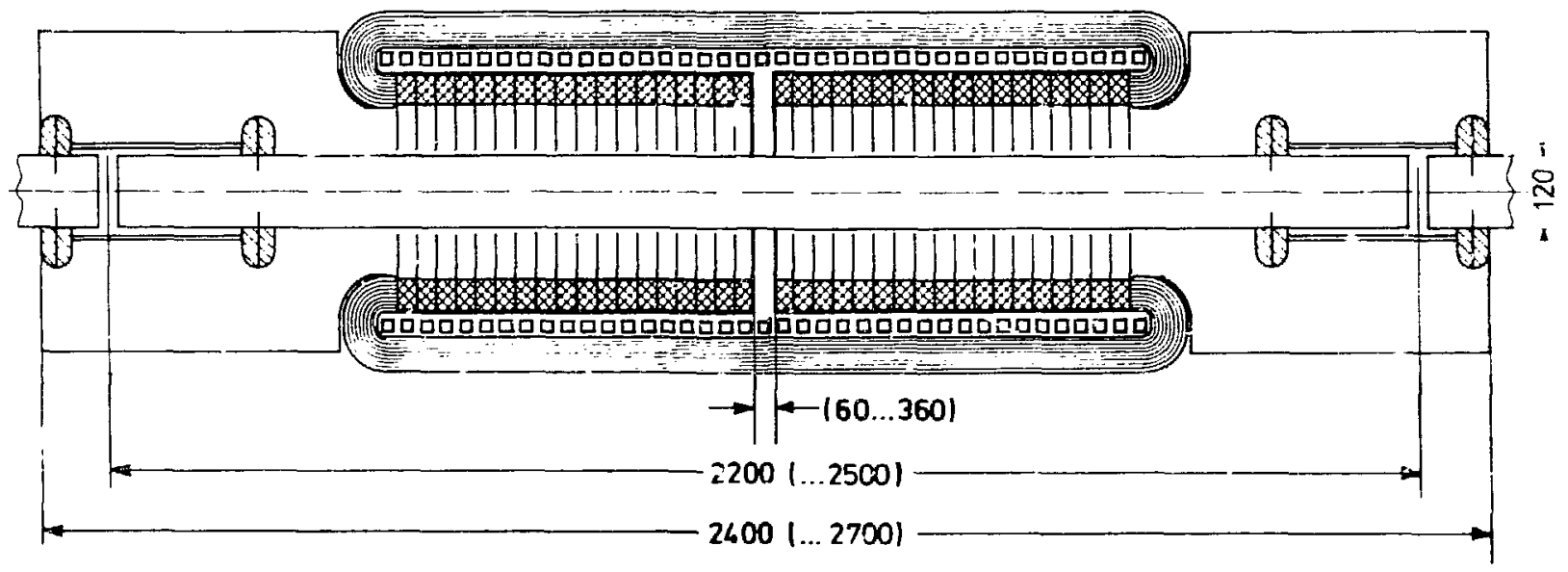

Fig. 4. Combination of two quarter-wave resonators in one accelerating unit. 
case it would be useful to move the two resonators apart by the missing distance and provide additional space for rf coupling and air cooling.

\section{LUMPARISON WITH MORE COMPLEX CAVITY GEOMETRIES}

In the preceding sections $I$ have tried to show that most of the critical problems in the LAMPF II cavities can be solved technically based on a simple coaxial quarter-wave resonator geometry. The question arises whether better or more economical solutions can be obtained by means of a more complex cavity georatry.

A drift-tube cavity design with the ferrites assembled in several smaller separate tuner units simflar to the FNAL booster cavities has been studied in more detail. The following advantages are expected in this geometry: (1) The dimensions of the ferrite elements can be chosen independent of the beam-tube dimensions and thus matched to other requirements. (2) Smaller tuner diameters facilitate the generation of the perpendicular bian field. (3) As indicated in Fig. 5, there is an attractive solution for closing the biasfield flux by means of an external yoke. (4) It seems possible to submerge the whole tuner assembly in a cooling bath or to use flood cooling with an 3ppropriate cooling liquid.

Calculations with the dimensions given in Fig. 5 and two double tuner units containing a ferrite volume similar to the coaxial bocster cavity led to ineffectively low drift-tube lengths. A larger number of tuner units are necessary. Studies on this geometry were not continued; the simple transulssion-line model used is probably not sufficient to get reliable data on similarly complex geometries. A more elaborate investigation was not possible in the time available but would be indispensable for a final judgment.

Compared with the drift tube and other structures considered, the coaxial cavity has one important advantage. The transmission-line calculations described in this report are only approximate in this case. However, due to its rotational symnetry, the simple coaxial geometry is the only case that allows application of much more prectse calculational methods sich as SUPERFISH or othet field-distribution programs. This feature allows calculation of most electric properties, reliable investigation of higher resonance modes, and of possibilities to influence these with a precision and reliability that can never be achieved in a less symmetric design. 


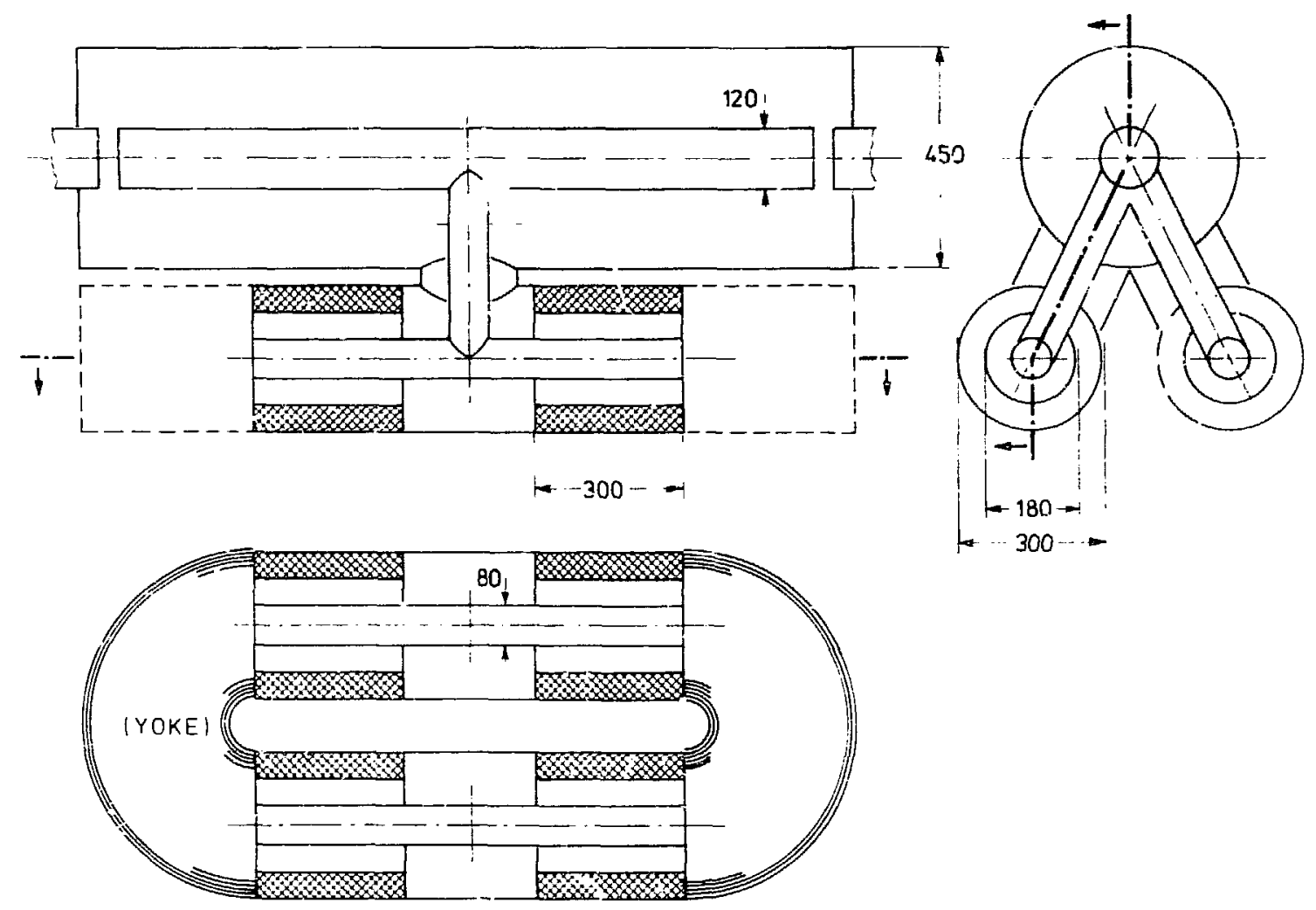

Fig. 5. Schematic of a drift-tube cavity with separate smaller tuner units.

\section{BEAM LOADING IN THE LAMPF II CAVITIES}

In every accelerator, beam loading becomes important when the power taken up by the beam becomes larger than the power dissipated in the cavity. A look at Tables I and II shows that beam loading will be a fundamental problem in LAMPF II.

Dne solution is to raise the power dissipation in the cavity to a level comparable to the power given to the beam. With the perpendicular-biased cavities, there would still be the advantage of the feasibility of larger gap voltages per cavity than in conventional systems. The losses would no longer appear in the ferrites but could be concentrated on components of the cavity that are easier to coo?.. Additional losses can be realized by bullding the cavity walls, especially the inner conductor, out of stainless steel or more lossy waterial. The given inner-conductor diameter allows 100-mm aperture diameter and 10-mm walı thickness for cooling channels, etc. However, because of its poor electric efficiency, this method should be avoided if possible. 
The extent to which closed-loof control methods can be used instead of or in combination with additional loading of the cavity needs thorough study. It is expected that high quality factors, which mean a decreased time constant and response time of the cavities, raise the chances of solving tha beamloading problems by control methods.

\section{ACKNOWLEDGMENTS}

I thank H. A. Thiessen for the invitation to Los Alamos and for giving me the opportinity to learn more about new ideas in the fleld of ferrite-tuned synchrotron cavities. Also, I thank Roger D. Carlini, Carolyn Colston, and all other members of the LAMPF II group for their kind and friendly collaboration.

\section{REFERENCES}

1. I. M. Earley, G. P. Lawrence, and J. M. Potter, "Rapidly Tuned Buncher Structure for the Los Alamos Proton Storage Ring," IEEE Trans. Nucl. Sci. NS-30 (4), 3511 (1983).

2. Lawrence M. Earley, Henry A. Thiessen, Roger D. Carlini, and James M. Potter, "A High-Q Ferrite-Tuned Cavity, Los Alamos National Laboratory report LA-9823-MS (August i983).

3. Roger D. Carlini, Henry A. Thiessen, and James M. Potter, "A High- $Q$ Perpendicular-Biased Ferrite-Tuned Cavity," Los Alamos National Laboratory report LA-9946-MS (January 1984).

4. C. Arnaud, H. Bargamann, H. P. Kindermann, H. Kuhn, W. Middelkoop, G. Nassibian, W. Pirkel, K. H. Reich, C. Rufer, and D. Zanaschi, "Finding Out About Ferrites," CrRN Courier 12 (11), 364 (1972).

5. J. E. Griffin and G. Nicholis, "A Review of Some Dynamic Loss Properties of N1-Zn iccelerator RF System Ferrite," IEEE Trans. Nucl. Sci. NS-26 (3), 3955 (1979).

6. G. Rakowsky and A. Tranis, "Nonlinear Effects in 'Linear Ferrites at High rf Flelds," IEEE Trans. Nucl. Sci. NS-16 (3), 543 (1969).

7. U. Bigliani, G. Nassibian, K. H. Reich, and D. Zanaschi, "The rf Accelezating System for the CERN PS Booster," IEEE Trans. Nucl. Sci. NS-18 (3), 233 ( 1971 ).

8. H. v. d. Heide, "Measurement of Time Effects in the Radiofrequency $Q$ of Ni-Zn Ferrites Containing Three-Valent Cobalt," National Laboratory der Philips Gloeilampenfabricken, Tech. Note 78/71, Eindhoven (1971). 
9. J. A. Dinkel, Q. A. Kerns, L. A. Klalsner, and G. S. Trol, "NkL Booster and Storage-King rf Systems," IEEE Trans. Nucl. Sci. NS-16 (3), 510 (1969).

1.. L. L. Reginato and R. H. Smith, "Application of the Two-iower-Supply Method to the Eerrite Blas of an If Resonator of a Rapid Cycling Syachrotron," Lawrence Berkeley Laboratory report UCRL-18489 (1969).

11. G. Rakowsky, "RE Accelerating Cavities for AGS Conversion," IEEE Trans. Nucl. Sci. NS-14 (3), 315 (1967).

12. J. E, Griffin and Q. A. Kerns, "NAL Main-Ring Cavity Test Results," IEEE Trani. Nucl. Sci. NS-18 (3), 241 (1971).

1?. J. F. Bridges, D. E. Johnson, and J. E. Griffin, "Dlelectric Property Measurements on Large Alumina Vacuum Seals Used on Fermilab Accelerator rf Cavities," IEEE Trans. Nucl. Sci. NS-22 (3), 1296 (1975), 
APPENUIX

APPROXIMATION FOR THE DESIGN OF THE ACCELERAT ING CAVITIES

The general case ỗ a coaxial ferrite-tuned quarter-wavi regonator can be described with the resonator geometry shown in $\mathrm{FIE}$. A-1. It consists of two basic untts, a foreshortened plece of coaxlal 1ine (section A-B) partly iflled with ferrite naterial and a second open-euded piece of coaxial line (section B-G) contalning no ferrite. Both unfts can be treated with known transmission-line formulae. All ferrite-tuned accelerating cavitles used in synchrotrons to the present can be understood as a combination of one or more of these basic units.

The turer section ( $\operatorname{section} A-B$ ) of the cavity can be treated as a foreshorcened flece of transmission line filled entirely with a dielectric with average properties $\mu_{\text {eff }}$ and $\varepsilon_{\text {ef }}$. The electric parameters of the tuner are then given by the ioll jwing expressions:

Effective permeability:

$$
\mu_{\text {ef }}=\left(\mu_{\text {mat }}-1\right) \cdot \phi+1
$$

Effective permittivity:

$$
\varepsilon_{\text {eff }}=\frac{\varepsilon_{\text {mat }}}{\phi+(1-\phi) \cdot \varepsilon_{\text {mat }}}
$$
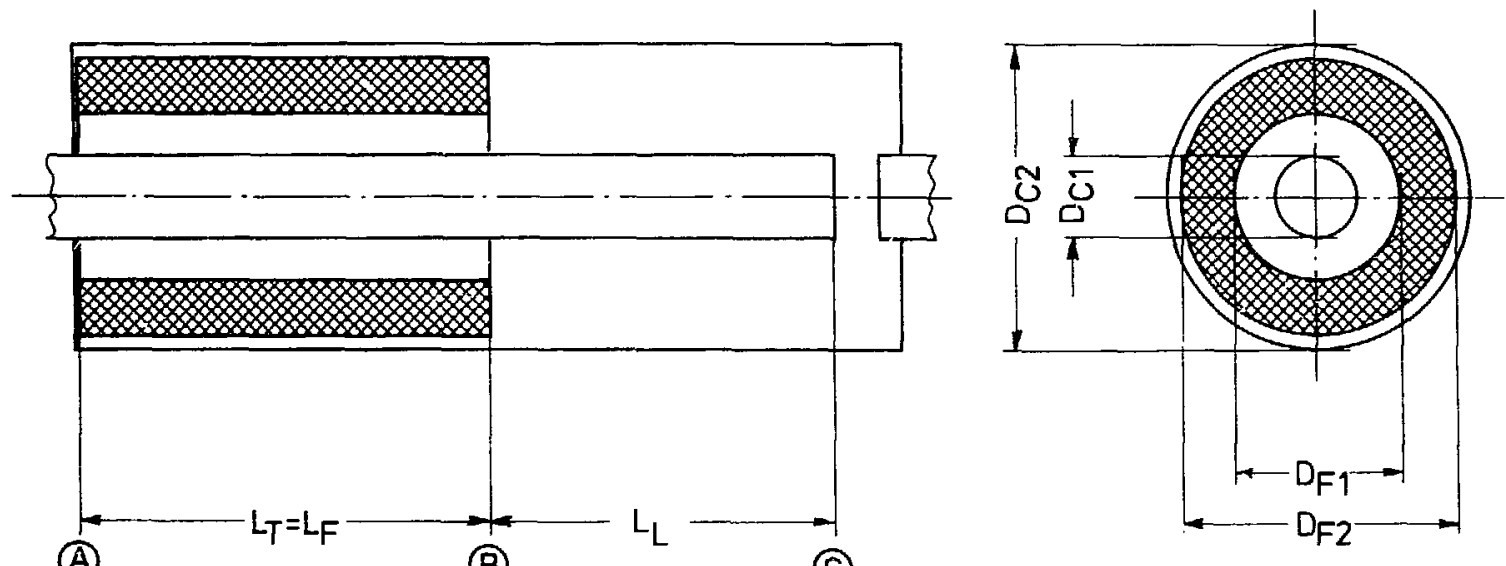

(A)

(B)

(G)

F1g. A-1. Schematic section through a ferrite-tuned coaxlal quarter-wave resonator. 
Filling factor:

Wavelength on tuner:

Characteristic tuner impedance:

Current on the tuner:

Voltage on the tuner:

Maximum tuner current:

Impedance of the tuner:

Mägnetic field:

Magnetic power density:

Voltage across the ferrite:

Electric field in ferrite:

Electric power density:

$$
\mathrm{U}_{\mathrm{Fe}}(\mathrm{x})=\frac{\varepsilon_{\text {eff }}}{\varepsilon_{\text {mat }}} \cdot \mathrm{U}_{\mathrm{T}}(\mathrm{x})
$$

$$
E_{\mathrm{Fe}}(x, r)=\frac{U_{\mathrm{Fe}}(x)}{r \cdot \ln \left(D_{\mathrm{oF}} / D_{1 F}\right)}
$$

$$
\begin{aligned}
\phi \quad & =\frac{\ln \left(D_{\mathrm{F} 2} / D_{\mathrm{F} 1}\right)}{\ln \left(\bar{D}_{\mathrm{C} 2} / D_{\mathrm{Cl}}\right)} \\
\lambda_{\mathrm{T}} & =\lambda_{\mathrm{vac}} /\left(\mu_{\mathrm{eff}} \cdot \varepsilon_{\mathrm{Ef} f}\right)^{1 / 2}
\end{aligned}
$$$$
z_{c T}=\left(\mu_{\text {eff }} / \varepsilon_{\text {eff }}\right)^{1 / 2} \cdot 60 \cdot \ln \left(\mathrm{L}_{\mathrm{C} 2} / \mathrm{D}_{\mathrm{Cl}}\right)
$$$$
I_{T}(x)=I_{T}(0) \cdot \cos \left(\theta_{T} \cdot x\right)
$$$$
\mathrm{U}_{\mathrm{T}}(\mathrm{x})=\mathrm{j} \cdot \mathrm{Z}_{\mathrm{cT}} \cdot \mathrm{I}_{\mathrm{T}}(0) \cdot \sin \left(\theta_{\mathrm{T}} \cdot \mathrm{x}\right)
$$$$
I_{T}(0)=-j \cdot \frac{U_{T}\left(L_{T}\right)}{Z_{c T} \cdot \sin \theta_{T} \cdot L_{T}}
$$$$
\mathrm{x}_{\mathrm{T}}\left(\mathrm{L}_{\mathrm{T}} ;=-\mathrm{j} \cdot \mathrm{z}_{\mathrm{cT}} \cdot \tan \left(\theta_{\mathrm{T}} \cdot \mathrm{L}_{\mathrm{T}}\right)\right.
$$$$
H_{T}(x, r)=\frac{I_{T}(x)}{2 \pi \cdot r}
$$$$
\mathrm{dP}_{\mathrm{w}} / \mathrm{dV}=\frac{\omega_{\mathrm{r}} \cdot \mu_{\text {iuat }} \cdot \mu_{0} \cdot \mathrm{H}_{\mathrm{T}}(\mathrm{x}, \mathrm{r})^{2}}{2 \cdot \mathrm{Q}_{\text {mmat. }}}
$$

$\mathrm{dPe} / \mathrm{dV}=\frac{\omega_{r} \cdot \varepsilon_{\mathrm{mat}} \cdot \varepsilon_{\mathrm{o}}=E_{\mathrm{Fe}}(\mathrm{x}, \mathrm{r})^{2}}{2 \cdot \mathrm{Q}_{\text {emat }}}$

The electric parameters of the ferrite-free section $B-C$, when calculated from the open end $G$ toward point $C$, are given by the following expressions:

Voltage distribution:

$$
U_{L}(x)=U_{G}\left(x_{G}\right) \cdot \cos \left(\theta_{L} \cdot x\right) ; \theta_{L}=2 \pi / \lambda_{\text {vac }}
$$




$$
\begin{array}{ll}
\text { Current distribution: } & I_{L}(x)=j \cdot \frac{1}{Z_{c L}} \cdot U_{G}\left(x_{G}\right) \cdot \sin \left(\theta_{L} \cdot x\right) \\
\text { Impedance of nnen 1ine: } & x_{L}\left(x_{B}\right)=-j \cdot Z_{C L} \cdot \cot \left(\theta_{L} \cdot L_{L}\right)
\end{array}
$$

The gap capacitance has been neglected here. It can be taken into account by increasing the free line length $\tau_{L}$ by a certain length $\Delta L$. For resonance of the whole system, the ferrite permeability $\mu_{\text {mat }}$ has to be varied to fulf $\hat{x} 11$ the condition $\mathrm{x}_{\mathrm{T}}\left(\mathrm{L}_{\mathrm{T}}\right)=-\mathrm{X}_{\mathrm{L}}\left(\mathrm{L}_{\mathrm{L}}\right)$. 